\title{
Development of Community Pharmacy Characteristics Questionnaire: Application of Cognitive Interviewing
}

Megan G. Smith, PharmD, BCACP, Assistant Professor ${ }^{1}$; Stefanie P. Ferreri, PharmD, BCACP, CDE, FAPhA, Clinical Professor ${ }^{2}$; Rachel Stafford, PharmD, Assistant Professor ${ }^{3}$ Ben Teeter, PhD, Assistant Professor ${ }^{3}$ Kea Turner, MPH, MA, doctoral candidate 4 Stevie Veach, PharmD, BCACP, Clinical Assistant Professor ${ }^{5}$; Christopher M. Shea, PhD, MA, MPA, Associate Professor 6

${ }^{1}$ Department of Pharmacy Practice, University of Arkansas for Medical Sciences, Little Rock, AR

2Division of Practice Advancement and Clinical Education, UNC Eshelman School of Pharmacy, Chapel Hill, NC

${ }^{3}$ University of Arkansas for Medical Sciences, Little Rock, AR

${ }^{4}$ Department of Health Policy and Management, Gillings School of Global Public Health, University of North Carolina-Chapel Hill, Chapel Hill, NC

${ }^{5}$ University of lowa College of Pharmacy, lowa City, IA

${ }^{6}$ Department of Health Policy and Management, UNC Gillings School of Global Public Health, Chapel Hill, NC

\section{ABSTRACT}

Background: A questionnaire specific to community pharmacy characteristics, such as staffing models for clinical activities and business operations, does not exist. As community pharmacy practice expands, it is important to characterize how pharmacies are changing for outcomes research. The aim of this study was to conduct cognitive interviewing with community pharmacists to gain feedback on the formatting, readability, and content of items measuring community pharmacy characteristics to develop such a questionnaire.

Methods: National surveys and previously developed survey work were reviewed to identify the following question categories: business operations, human resource management, division of clinical responsibilities, technology, and enhanced services. Questions for each domain were drafted and assessed for applicability across different states and level of importance by researchers in 3 different states. Using the "think aloud" method of cognitive interviewing to evaluate clarity in instructions, question items and response entry, an iterative process was established that included 3 rounds of interviews with discussion and modifications made by the research team between each round. Results: $A$ total of thirteen cognitive interviews across 3 rounds were conducted via telephone and lasted between 30 and 60 minutes. Time for participant pharmacists to complete the questionnaire ranged from 12 minutes to 30 minutes. The interviews revealed areas of ambiguity, and missing response options for the variety of business structures. The question categories with the most problematic items were business operations, human resource management, and division of clinical responsibilities.

Conclusion: Using cognitive interviewing, a community pharmacy questionnaire focusing on operational characteristics was developed. Future research is warranted to test the organizational characteristics defined in this paper with a larger sample size representing multiple states.

Keywords: community pharmacy; surveys and questionnaires; cognitive interviewing

\section{INTRODUCTION}

Developing a questionnaire that assesses community pharmacy characteristics is critical for informing future research on community pharmacy practice. As community pharmacies continue to transform their organizations-such as expanding and diversifying clinical services, ${ }^{1,2}$ redefining pharmacy staff roles, ${ }^{3,4}$ or joining integrated networks (e.g. Community Pharmacy Enhanced Services Network (CPESN)) $)^{5}-$ it is important to characterize how community pharmacies are changing. By better understanding the organizational characteristics of community pharmacies, researchers can identify which characteristics are associated with improvements in patient outcomes.

Corresponding author: Megan G. Smith, PharmD, BCACP Assistant Professor, Department of Pharmacy Practice University of Arkansas for Medical Sciences 4301 W. Markham Street; Little Rock, AR 72205 Email: msmith4@uams.edu
Although several organizations administer questionnaires that capture pharmacy characteristics, ${ }^{6,7}$ these surveys collect information on a wide-variety of topics and are not specifically designed to provide a comprehensive summary of community pharmacy characteristics. The Pharmacy Workforce Center administers the National Pharmacist Workforce Survey, ${ }^{6}$ which collects information on the pharmacist workforce including demographics, work environment, and quality of work life. While it captures pharmacy characteristics such as type of pharmacy and type of services, the unit of analysis is the pharmacist and therefore focuses on the work done by the pharmacist rather than the work performed by the entire pharmacy staff. The National Community Pharmacists Association administers a questionnaire to pharmacy owners, the NCPA Digest, which collects information on pharmacy characteristics such as staffing, clinical services, and technology ${ }^{7}$. The scope of this questionnaire is broad, however it does not provide detailed information on the different types of staff that might be involved in enhanced services delivery or how community pharmacies divide up clinical responsibilities. Therefore, a community pharmacy characteristics assessment 
is needed that captures information such as demographics, business operations, human resource management, pharmacy trainees, division of clinical responsibilities, and technology and enhanced services.

Cognitive interviewing is an established method used to develop standardized measures, reduce response error, and identify potential problems with question items including the formatting, overall readability, and item content. ${ }^{8}$ It has proven particularly useful for research that may include sensitive topics such as patient symptom assessment, ${ }^{9,}{ }^{10}$ or vulnerable populations such as children. ${ }^{10,11}$ It is also useful for research topics where there are limited validated measures ${ }^{12}$-such as research on community pharmacy characteristics.

The aim of this study was to develop a questionnaire of community pharmacy characteristics using cognitive interviewing with community pharmacists to gain their feedback on the formatting, readability, and content. In this paper, we describe types of information that participants identified as particularly problematic to report through a questionnaire approach.

\section{METHODS}

\section{Selection of Categories for Testing}

Questions and categories used in other national pharmacy surveys ${ }^{6,13}$ and the authors' previously developed work ${ }^{14}$ were reviewed. From these, the following categories were developed: business operations, human resource management, division of clinical responsibilities, technology, and enhanced services. The principal investigator drafted questions for each of the categories. Within the business operations category, questions covered pharmacy practice setting, type of ownership, and pharmacy accreditations or certifications achieved. For the human resource management category, questions focused on number of employees, FTE equivalents, and trainees. In the division of clinical responsibilities category, questions were written to assess how clinical activities are managed and delegated amongst staff. Questions about the different pharmacy management systems and electronic platforms were included in the technology category. Lastly, the enhanced services category included questions about the types of services offered in each pharmacy beyond dispensing. The members of the research team from North Carolina reviewed the first draft of the questionnaire and modifications were made. Next, all research team members reviewed the second draft to assess the applicability of each question to their respective state. This assessment was included to account for variety in state practice laws and terminology. All research members also assessed the level of importance of each question.

After all team members reviewed the questionnaire, two conference calls were held to discuss items of concern and item importance. During the initial conference call, general consensus was reached about the desired length of the questionnaire and wording of the questions. Any questions that were found to be confusing were flagged for modification by the principal investigator. After the initial conference call, all suggested modifications were made and unnecessary questions were deleted. The revised questionnaire was then sent to the research team for review 2 weeks prior to the second conference call. During the second conference call, all modifications were discussed and the final version of the questionnaire to be pilot tested was agreed upon by all research team members.

\section{Cognitive Interviewing}

To further refine and pilot test the questionnaire, cognitive interviewing methods were utilized. Interviews were conducted via telephone by the primary investigator and lasted between 30 and 60 minutes. Time for participant pharmacists to complete the questionnaire ranged from 12 minutes to 30 minutes. To ensure concerns were being appropriately addressed, an iterative process was established that included 3 rounds of interviews with discussion and modifications made by the research team between each round. We used the "think-aloud" method 8,15 in which participants were instructed to verbalize their thought process in real-time as they answered each question. This method aims to facilitate participants' verbalization, but to intervene as little as possible. During each interview the principal investigator used reactive verbal probes, if needed, to find out additional information when participants had difficulty answering a question or if a question did not apply to their situation. For example, if it appeared the participant was having trouble with a question, the principal investigator would ask them to restate the question in their own words and take note of those changes. During each interview, written notes of substantive observations related to the functioning of the item (e.g. for years of operation one participant asked "for that location or our whole company?") were recorded on a printed version of the survey. Notes for each evaluated item were combined in aggregate across interviews and presented to the research team to identify common departures from the intention of the question desired by survey developers These notes and findings formed the basis for revisions in format, instructions, and items.

\section{Participant Recruitment}

For the cognitive interviews, we recruited individuals who represented a convenience sample of survey responders, specifically, pharmacists who were either owners or managers of community pharmacies. The authors estimated it would require 3-5 pharmacists per round based on previous experiences and published literature. ${ }^{8}$ An initial list of fifteen potential participants was created using contacts known to the research team. A research team member from Arkansas, North 
Carolina, and lowa were asked to submit at least 5 potential participants to the principal investigator. The principal investigator then contacted each potential participant via telephone for recruitment. During recruitment, each potential participant was given information about the purpose of the project, the nature of the questionnaire they would be pilot testing, and the anticipated time required for them to participate. Those who agreed to participate scheduled one hour-long appointment with the principal investigator. Participants were not remunerated for their time. The University of Arkansas for Medical Sciences Institutional Review Board exempted this research.

\section{RESULTS}

We conducted 13 cognitive interviews across 3 rounds to evaluate clarity in instructions, question items, and response entry. Table 1 summarizes the interview participants. Prior to conducting cognitive interviews, the community pharmacy characteristics questionnaire consisted of 56 total draft items. Based on feedback received during the cognitive interviews, demographic and other pharmacy characteristic items were added, for a total of 71 items with extensive branching logic. The category that increased by total number of questions the most was human resource management and the category that received the most item revision was division of clinical activities. The cognitive interviews revealed the types of information that were most problematic for participants to report, based on how the survey items were presented. There were no new categories identified; rather many of the problems involved ambiguity (e.g., in terms of which roles to consider) or insufficient specification in response options. The categories with the most problematic items were business operations, human resource management, and division of clinical responsibilities during rounds 1 and 2 of cognitive interviewing, which are presented in more detail below. Minor wording issues in technology and enhanced services categories were resolved after round 1 . Round three participants did not have difficulties answering any question in any category. Interviews were conducted June-July 2017 and revisions to questionnaire were completed in August 2017.

\section{Business Operations}

A primary challenge for participants responding to items in this category was how to account for multiple store locations, or multiple practice types (e.g. retail and compounding) for a single location. For these reasons, notes were added throughout the questionnaire to answer for the specific pharmacy national provider identifier (NPI) provided on the first page, and an option to select secondary practice types was added. Questions related to formal arrangements with health systems or other provider organizations were also problematic. The phrasing of "Does your pharmacy have a formal practice relationship, defined as a signed contract..." was unclear to some participants as a contract including a payment structure. Therefore, "contract" was changed to "agreement". Formatting was changed from 3 questions about the practice agreement and privileges to a matrix in order to better allow respondents to differentiate the privileges by type of organization (i.e., health system vs. individual provider). The matrix allowed respondents to see all of the information upfront and eliminated this confusion on subsequent rounds.

\section{Human Resource Management}

Another prominent challenge for respondents was deciding which staff positions to include in counts of staff, such as items related to full and part-time employees and FTE equivalents. Several participants asked if they should report the total number of employees for the company as compared to one location, therefore, section instructions were updated to answer per location based on the NPI entered on the first page. Additionally, participants asked if trainees should be included as employees. A sub-section following human resource management was entirely devoted to pharmacy trainees, so consequently directions were added to not include trainees such as residents, students, and interns for each employee type.

\section{Division of Clinical Responsibilities}

The first round of interviews uncovered that items captured information about the number of pharmacists and number of hours worked but were not effective in terms of gathering information about how clinical responsibilities are managed. For this reason, this section underwent the most revision. For example, instead of being asked how many pharmacists work per shift, participants were provided with response options briefly describing staffing models for clinical responsibilities (e.g., "Only one pharmacist works at a time managing both dispensing and clinical responsibilities"). In addition, an openended response was added to allow respondents to clarify their responses about the staffing models. Some respondents had additional roles, such as clinical coordinators, that were not represented in this category. Therefore, a closed-ended item was added for a coordinator role along with an openended question for the number of stores managed. A table summarizing revisions is presented in Table 2.

\section{DISCUSSION}

This paper is the first we are aware of that attempts to identify standard organizational characteristics for community pharmacies. There are several examples of community pharmacies that have successfully shifted their business models away from high prescription volume to patient care services. These pharmacies are adequately staffed to ensure that clinical services can be provided, they emphasize patient care, and work to ensure that every patient is achieving his or her desired therapeutic outcomes. ${ }^{2,14,16}$ However, a method for capturing the organizational characteristics of these 
successful pharmacies is missing in the literature. The characteristics defined in this paper utilized cognitive interviews with pharmacists that self-reported delivery of patient care services.

During our cognitive interviews we categorized community pharmacy characteristics into five areas: business operations, human resource management, division of clinical responsibilities, technology and enhanced services. Of these, pharmacies had the most difficulty answering questions in the first three areas. These areas required extensive revisions from the researchers. In the first two rounds, questions in business operations were problematic due to changes in operations over time (e.g. pharmacy offered durable medical equipment in the past, but not currently). This category also included questions regarding formal practice relationships with health systems and local providers. Participants were unsure if to include general protocol for immunizations and suggested to combine practice relationship (i.e. health system vs specific provider) type with privileges included in the agreement. The human resource management category was problematic due to cross-trained employees, pharmacies with corporate structures, and multiple store ownership. Several participants also asked if trainees (e.g. interns, students, residents) should be included and counted as employees. The division of clinical responsibilities category was problematic in that the questions did not adequately collect the time spent on clinical activities and by whom. Some pharmacies also employed or dedicated some hours to coordinator or managerial type positions, which was not accounted for in the survey.

Improving these survey items is important to determine which organizational characteristics lead to successful implementation of patient care service models in community pharmacies. The availability of resources differs across pharmacies ${ }^{17}$ and this study is the first we are aware to try to come to consensus on the availability and quantification of resources. As such, we feel our results can provide additional information that prior surveys do not gather. Anecdotally, several different pharmacy staffing models (e.g., dedicated clinical pharmacists, scheduling overlap hours) have become more common, but it is unclear whether these models or other, independent factors are associated with the successful implementation of specific pharmacy services. This is why the organizational characteristics including business operations, human resource management, division of clinical responsibilities, technology and enhanced services developed from this paper must be utilized in future community pharmacy research.
This survey was developed with a small sample size of independent pharmacy owners from three states. In order to test the organizational characteristics defined in this paper, future research is warranted in all types of community pharmacies, including mass merchandisers, national chains, grocery stores and other outpatient pharmacy settings representing multiple states. The next step for our research is to distribute to a larger group of pharmacies, which can enable analysis to determine if individual items can be grouped into indices to represent various categories of characteristics (i.e. human resources, business operations). As the profession evolves from fee-for-service to value-based models, research will be needed to see how community pharmacies are changing key facets of their organization (e.g., staffing models, business operations) in response.

\section{CONCLUSION}

By understanding organizational characteristics of community pharmacies, researchers can identify which characteristics are associated with practice-based research outcomes. This study categorized five characteristics including business operations, human resource management, division of clinical responsibilities, technology and enhanced services. A standard set of organizational characteristics for community pharmacies will help future researchers better assess how these characteristics affect pharmacy performance.

Acknowledgements: Michael Andreski, RPh, MBA, PhD at Drake University College of Pharmacy and Health Sciences for guidance on development of questionnaire questions.

\section{Conflicts of interest: none}

\section{References}

1. Doucette WR, Kreling DH, Schommer JC, Gaither CA, Mott DA, Pedersen CA. Evaluation of community pharmacy service mix: evidence from the 2004 National Pharmacist Workforce Study. J Am Pharm Assoc (2003). 2006;46:348-355.

2. Doucette WR, Rippe JJ, Gaither CA, Kreling DH, Mott DA, Schommer JC. Influences on the frequency and type of community pharmacy services. J Am Pharm Assoc (2003). 2017;57:72-76 e71.

3. Schultz JM, Jeter CK, Martin NM, Mundy TK, Reichard JS, Van Cura JD. ASHP Statement on the Roles of Pharmacy Technicians. Am J Health Syst Pharm. 2016;73:928-930.

4. Nkansah N, Mostovetsky O, Yu C, et al. Effect of outpatient pharmacists' non-dispensing roles on patient outcomes and prescribing patterns. Cochrane Database Syst Rev. 2010:CD000336.

\section{LIMITATIONS}


5. CPESN USA. What is CPESN? 2017; https://www.cpesn.com/what-is-cpesn/. Accessed September 25, 2017.

6. Pharmacy Workforce Center. 2014 National Pharmacist Workforce Survey: http://www.aacp.org/resources/research/pharmacy workforcecenter/Documents/FinalReportOfTheNatio nalPharmacistWorkforceStudy2014.pdf. Accessed September 25, 2017.

7. National Community Pharmacy Association. NCPA 2016 Digest:

http://www.ncpa.co/pdf/digest/2016/2016-ncpadigest-spon-cardinal.pdf. Accessed September 25, 2017.

8. Beatty PC, Willis GB. Research Synthesis: The Practice of Cognitive Interviewing. Public Opinion Quarterly 2007;71:287-311.

9. Pendlebury ST, Welch SJ, Cuthbertson FC, Mariz J, Mehta Z, Rothwell PM. Telephone assessment of cognition after transient ischemic attack and stroke: modified telephone interview of cognitive status and telephone Montreal Cognitive Assessment versus face-to-face Montreal Cognitive Assessment and neuropsychological battery. Stroke. 2013;44:227229.

10. Irwin DE, Varni JW, Yeatts K, DeWalt DA. Cognitive interviewing methodology in the development of a pediatric item bank: a patient reported outcomes measurement information system (PROMIS) study. Health Qual Life Outcomes. 2009;7:3.

11. Norris AE, Torres-Thomas S, Williams ET. Adapting cognitive interviewing for early adolescent Hispanic girls and sensitive topics. Hisp Health Care Int. 2014;12:111-119.
12. Teal R, Enga Z, Diehl SJ, et al. Applying Cognitive Interviewing to Inform Measurement of Partnership Readiness: A New Approach to Strengthening Community-Academic Research. Prog Community Health Partnersh. 2015;9:513-519.

13. Community Pharmacy Impact Census. Vol 2017: National Community Pharmacists Association; 2016.

14. Smith MG, Shea CM, Brown P, Wines K, Farley JF, Ferreri SP. Pharmacy characteristics associated with the provision of medication management services within an integrated care management program. J Am Pharm Assoc (2003). 2017;57:217-221 e211.

15. Willis GB, Artino AR, Jr. What Do Our Respondents Think We're Asking? Using Cognitive Interviewing to Improve Medical Education Surveys. J Grad Med Educ. 2013;5:353-356.

16. Doucette WR, McDonough RP, Herald F, Goedken A, Funk J, Deninger MJ. Pharmacy performance while providing continuous medication monitoring. J Am Pharm Assoc (2003). 2017;57:692-697.

17. Lounsbery JL, Green CG, Bennett MS, Pedersen CA. Evaluation of pharmacists' barriers to the implementation of medication therapy management services. J Am Pharm Assoc (2003). 2009;49:51-58. 
Table 1. Summary of participants in cognitive interviews

\begin{tabular}{|c|c|c|c|c|}
\hline $\begin{array}{l}\text { Round of } \\
\text { Interview }\end{array}$ & Participant & Role & Pharmacy Type & State \\
\hline \multirow[t]{5}{*}{1} & 1 & Owner & Multiple independents & Arkansas \\
\hline & 2 & Manager & Single Independent & Mississippi \\
\hline & 3 & Co-Owner & Single Independent & Arkansas \\
\hline & 4 & Owner & Single Independent & Wisconsin \\
\hline & 5 & Owner & Multiple Independents & Wisconsin \\
\hline \multirow[t]{5}{*}{2} & 6 & Owner & Multiple independents & Missouri \\
\hline & 7 & Manager & Multiple independents & Washington \\
\hline & 8 & Manager & Single independent & Alabama \\
\hline & 9 & Co-owner & Multiple independents & Arkansas \\
\hline & 10 & Owner & Single independent & Oklahoma \\
\hline \multirow[t]{3}{*}{3} & 11 & Owner & Single independent & Arkansas \\
\hline & 12 & Manager & Multiple independent & Arkansas \\
\hline & 13 & Manager & Multiple independent & Arkansas \\
\hline
\end{tabular}


Table 2. Selection of Revised Questionnaire Items

\begin{tabular}{|c|c|c|c|}
\hline & Original Item & Revised Item & Reason for revision \\
\hline $\begin{array}{l}\text { Business } \\
\text { operations }\end{array}$ & $\begin{array}{l}\text { How many total pharmacies } \\
\text { are under same ownership? }\end{array}$ & $\begin{array}{l}\text { What is the total number of licensed } \\
\text { pharmacies in } \\
\text { your organization or under same } \\
\text { ownership? }\end{array}$ & $\begin{array}{l}\text { Eliminated confusion with corporate } \\
\text { structures and non-dispensing locations }\end{array}$ \\
\hline $\begin{array}{l}\text { Human } \\
\text { Resource } \\
\text { Management }\end{array}$ & $\begin{array}{l}\text { How many full-time } \\
\text { equivalents (FTE) for each } \\
\text { personnel are employed at } \\
\text { your pharmacy? } \\
\text { Note: } 2 \text { half-time } \\
\text { employees equals } 1 \text { FTE } \\
\text { Example: } 2 \text { half-time plus } 1 \\
\text { full-time = } 2 \text { FTE } \\
\text { - } \quad \text { Pharmacists } \\
\text { - } \quad \text { Pharmacy technicians } \\
\text { - } \quad \text { Durable medical } \\
\text { - } \quad \text { Nutritionists } \\
\text { - } \quad \text { Physician's assistants } \\
\text { - } \quad \text { Nurse practitioners } \\
\text { - } \quad \text { Registered nurses }\end{array}$ & $\begin{array}{l}\text { How many full-time equivalents (FTE) } \\
\text { for each personnel are employed at } \\
\text { your pharmacy? } \\
\text { Note: } 2 \text { half-time employees equals } 1 \\
\text { FTE } \\
\text { Example: } 1 \text { half-time plus } 2 \text { full-time = } \\
\text { 2.5 FTE } \\
\text { - } \quad \text { Pharmacists } \\
\text { - } \quad \text { Pharmacy technicians } \\
\text { - } \quad \text { Physicians } \\
\text { - } \quad \text { Durable medical equipment } \\
\text { - } \quad \text { Registered Dietician } \\
\text { - } \quad \text { Physician's assistants } \\
\text { - } \quad \text { Nurse practitioners } \\
\text { - } \quad \text { Registered nurses } \\
\text { - } \quad \text { Dentists }\end{array}$ & $\begin{array}{l}\text { Nutritionist may encompass varying } \\
\text { levels of education or certification. } \\
\text { Registered dietician is a standardized } \\
\text { licensure }\end{array}$ \\
\hline $\begin{array}{l}\text { Division of } \\
\text { Clinical } \\
\text { Responsibilities }\end{array}$ & $\begin{array}{l}\text { Are } 2 \text { or more pharmacists } \\
\text { scheduled during the same } \\
\text { shift? }\end{array}$ & $\begin{array}{l}\text { Which description best aligns with } \\
\text { how clinical responsibilities are } \\
\text { managed at your pharmacy? } \\
\text { - } \quad \text { Dedicated full or part time } \\
\text { pharmacist(s) for clinical } \\
\text { responsibilities ONLY (i.e., with } \\
\text { little to no dispensing } \\
\text { responsibilities) } \\
\text { Only one pharmacist works at a } \\
\text { time managing both dispensing } \\
\text { and clinical responsibilities } \\
\text { Two or more pharmacists are } \\
\text { scheduled at the same time } \\
\text { (pharmacist overlap) to allow at } \\
\text { least } 1 \text { pharmacist to complete } \\
\text { clinical responsibilities outside of } \\
\text { dispensing workflow } \\
\text { Two or more pharmacists work at } \\
\text { the same time completing clinical } \\
\text { responsibilities within dispensing } \\
\text { workflow as time allows (e.g. } \\
\text { integrated with dispensing) } \\
\text { Other } \\
\text { Please provide any additional } \\
\text { responsication on how clinical } \\
\text { pharmacists }\end{array}$ & $\begin{array}{l}\text { The original intent of identifying division } \\
\text { of clinical pharmacist responsibilities is } \\
\text { better ascertained through the additional } \\
\text { response options. }\end{array}$ \\
\hline
\end{tabular}

